Kim, M. (2020). Instagram selfie-posting and young women's body dissatisfaction: Investigating the role of selfesteem and need for popularity. Cyberpsychology: Journal of Psychosocial Research on Cyberspace, 14(4), Article 4. https://doi.org/10.5817/CP2020-4-4

\title{
Instagram Selfie-Posting and Young Women's Body Dissatisfaction: Investigating the Role of Self-Esteem and Need for Popularity
}

\author{
Mihee Kim
}

Sejong University, Seoul, South Korea

\begin{abstract}
An online survey was conducted to explore how Instagram users' selfie-posting behavior affects their self-esteem and body dissatisfaction. Female college students from South Korea $(N=321)$ participated in the survey. Results showed that Instagram users' selfie-posting was positively related to their self-esteem. Moreover, Instagram users' self-esteem mediated the relationship between their selfie-posting behavior and body dissatisfaction. Findings showed that Instagram users' selfie-posting behavior may positively influence their self-esteem, which may consequently contribute to reducing their body dissatisfaction. Such an indirect effect of selfie-posting was moderated by Instagram users' levels of the need for popularity. The indirect influence of selfie-posting on body dissatisfaction through self-esteem was only significant among those with low or moderate levels of the need for popularity. This suggests that those with lower levels of the need for popularity can benefit more from posting their selfies. These findings advance the emerging literature on the effects of selfie-posting by providing a moderated mediation model of selfie-posting and body image concerns.
\end{abstract}

Keywords: Selfie-posting; body dissatisfaction; self-esteem; need for popularity; Instagram

\section{Introduction}

Selfie-posting on social networking sites (SNS) is a unique and popular way of self-presentation (J. W. Kim \& Chock, 2017). SNS users share their selfies showing positive or desirable images of themselves to their online audiences (Chua \& Chang, 2016; Halpern et al., 2017). Taking and posting selfies have become an essential part of everyday lives especially for young people (P. Taylor, 2014). With the growing popularity of selfies, researchers have examined the effects of selfie activities on young women's body disturbance such as body dissatisfaction (e.g., Fardouly \& Rapee, 2019; Mills et al., 2018; Tiggemann et al., 2020; Vendemia \& DeAndrea, 2018). Recent research has demonstrated that selfie-viewing leads to social comparisons and the internalization of the beauty ideal, which contributes to increasing young women's body image concerns (e.g., Chang et al., 2019; Wang et al., 2019; J. Yang et al., 2020).

Prior research has shown that different types of SNS use (i.e., browsing, posting, interacting) have different impacts on young people's psychological well-being such as depressed mood (Frison \& Eggermont, 2017) and loneliness (C. Yang, 2016). These studies suggest that the effects of selfie-posting on body image may be inconsistent with those of selfie-viewing. Some studies have indicated that the frequency of selfie-posting is associated with decreased body dissatisfaction (Butkowski et al., 2019; Cohen et al., 2018), increased body satisfaction (Ridgway \& Clayton, 2016) and body esteem (Chang et al., 2019). However, why and how selfie-posting is connected with decreased body dissatisfaction remains largely unexplained. Existing studies have only offered a conjecture that those who post selfies may get the positive reinforcement of their appearance, which may decrease their body 
dissatisfaction (e.g., Cohen et al., 2018). To date, no research has explicitly investigated the mechanisms by which selfie-posting behavior can decrease SNS users' body dissatisfaction. This study fills this gap in the body image literature by testing a mediating role of self-esteem in the relationship between Instagram users' selfie-posting behavior and their body dissatisfaction.

Furthermore, I also attempt to explore the boundary conditions of Instagram selfie-posting effects. Instagram selfie-posting may not have the same consequences for everyone. The relationships among selfie-posting, selfesteem, and body dissatisfaction may be conditional on other factors such as a need for popularity that is a strong determinant of SNS use (Utz et al., 2012). Based on previous studies demonstrating the relationship between individuals' need for popularity and their SNS use (e.g., Utz et al., 2012; Utz \& Beukeboom, 2011), I expect that the effect of selfie-posting on self-esteem will be contingent on Instagram users' need for popularity. Finally, I propose a moderated mediation model in which the indirect effect of female college students' selfie-posting behavior on their body dissatisfaction through self-esteem may be moderated by their levels of the need for popularity.

Given the increasing prevalence of Instagram selfie-posting among young women (Dhir et al., 2016), it is important to investigate whether selfie-posting behavior provides young women with psychological benefits or not. In testing the proposed moderated mediation model, the findings of this study would provide valuable insights to enhance our understanding of selfie-posting behavior's potential implications for young women's self-esteem and body image concerns.

\section{The Mediating Role of Self-Esteem in the Relationship Between Selfie-Posting and Body Dissatisfaction}

Selfie-posting is one of the forms of online self-presentation (Chua \& Chang, 2016). Technological affordances of the Internet such as asynchronicity and editability significantly affect people's self-presentation (Walther, 1996). Asynchronous systems of the Internet provide individuals with "almost unlimited time for editing, composing, sending, and retrieving messages" (Hesse et al., 1988, p. 151). Such technological features have allowed individuals to easily emphasize positive self-images and desirable impressions of themselves, which encourages selective selfpresentation online. The selective self-presentation was originally advanced with text-based online communication. Hancock and Toma (2009) have enlarged the scope of selective self-presentation to visual works of self-expression such as online profile photographs. Similar to text messages, profile photographs of online date sites were found to be carefully chosen and digitally editable (Hancock \& Toma, 2009; Toma \& Hancock, 2010). Prior research shows that the enhancement of profile pictures can lead to a high likelihood of success in online dating (Gibbs et al., 2006). Similar to online daters, SNS users also participate in the selective self-presentation by uploading information or photographs that make themselves look attractive, positive or ideal (Bergman et al., 2011; Manago et al., 2008; Mendelson \& Papacharissi, 2010; Siibak, 2009; Zhao et al., 2008). This selective selfpresentation on SNS was found to be positively related to online life satisfaction (Y. Kim \& Baek, 2014) and subjective well-being (J. Kim \& Lee, 2011).

Self-esteem is defined as an individual's self-evaluation of oneself (Rosenberg, 1965). Self-esteem indicates how people feel and think about their worth, value, importance, or abilities (Rosenberg, 1965). As online selfpresentation has become a part of young people's everyday activities (Chua \& Chang, 2016), researchers have investigated how online self-presentation influences individuals' self-esteem. For instance, Toma (2013) has shown that SNS users can preserve a positive self-image and cope with threatening situations through viewing highly desirable self-presentation on SNS. After experiencing an ego threat (i.e., exposure to negative feedback), SNS users were found to unconsciously choose to browse their SNS profile page containing the happy side of themselves. After viewing their profile page, they appeared to restore the perceived worth of the self (Toma \& Hancock, 2013).

Such positive effects of selective self-presentation on self-esteem can be explained by the positive illusion theory (S. E. Taylor \& Armor, 1996). The theory posits that those with positive illusions such as self-aggrandizement, unrealistic optimism, and exaggerated perceptions of control are more likely to successfully adjust to stressful or self-threatening events (S. E. Taylor \& Armor, 1996). Furthermore, levels of happiness and contentment are found to be associated with positive self-concepts, illusory beliefs of control, and optimism concerning the future (S. E. Taylor \& Armor, 1996). That is, people's positive illusions of themselves can increase levels of positive feelings such as subjective well-being (J. Kim \& Lee, 2011) and happiness (S. E. Taylor \& Brown, 1988). 
SNS users' selfie-posting as a form of selective self-presentation may play a role in generating positive illusions of themselves. SNS users tend to post their beautiful or flawless selfies for gathering audiences' feedback they expect (Mascheroni et al., 2015). Halpern et al. (2017) explained this tendency by using the self-perception theory which proposes that individuals shape their attitudes by looking at their own behaviors (Bem, 1972). This theory suggests that SNS users determine their attitude towards themselves from observing their acts of self-presentation (Kelly \& Rodriguez, 2006). Based on positive feedback from audiences, SNS users may interpret the meaning of their selfie-posting behavior and adjust their perceptions of themselves. Such perceptions can influence their subsequent selfie-posting behavior (Halpern et al., 2017). Following the self-perception theory, Halpern et al. (2017) argued that SNS users create an "ideal persona" by continually posting selfies that can attract positive feedback from their audiences.

Moreover, selfie-posters can internalize the idealized persona that they build via selfies (Halpern et al., 2017). The internalization of positive traits of the self-presentation may allow selfie-posters to build positive illusions of themselves. As mentioned earlier, individuals consciously or subconsciously make efforts to take, select, and edit selfies in order to show a preferred and hoped-for version of themselves before posting them on their SNS (Chua \& Chang, 2016; Mendelson \& Papacharissi, 2010). Hence, SNS selfies can be a tool of more selective self-expression compared to SNS photographs taken by others. This suggests that selfies may be more apt as a vehicle for the internalization of an ideal illusion of the self rather than photographs taken by others. Such selfie-posters' positive illusions of themselves may help to construct a positive self-image and boost their self-worth that may be lacking in offline life (Chua \& Chang, 2016). In other words, Instagram users' selfie-posting behavior may satisfy their fundamental desire to perceive themselves to be worthy and valuable by producing positive illusions of themselves.

In sum, Instagram users' repeated selfie-posting behavior can result in the internalization of idealized or positive traits that their selfies attain, which may contribute to enhancing their positive illusions of themselves. Consequently, this may lead to raising their self-appraisals and changing their self-concept (Kelly \& Rodriguez, 2006; Schlenker et al., 1994). Therefore, it is plausible to expect that Instagram users' selfie-posting behavior can play an important role in boosting their self-esteem.

Low self-esteem has been known to closely related to young women's negative body image such as body dissatisfaction and body shame (Paxton et al., 2006). For instance, Fingeret and Gleaves (2004) found self-esteem indirectly influences body dissatisfaction through the internalization of appearance standards. In a similar vein, Tylka and Sabik (2010) have shown that low self-esteem predicted body surveillance, body comparison, and body shame. Those with high self-esteem incline to like or value themselves and accept their physical appearance as it is (Fitch, 1970). Thus, they may not need to monitor their body and compare it with others' bodies. In contrast, those who have low self-esteem tend to dislike or devalue themselves (Fitch, 1970). Also, they may not have confidence in their physical appearance. Therefore, they are more likely to vigilantly monitor their physical appearance and compare their physical appearance against others' appearances (Mercurio \& Landry, 2008; van den Berg et al., 2007). As a consequence, those with low self-esteem are more likely to experience body shame (Tylka \& Sabik, 2010). In sum, the relevant literature has provided evidence that low self-esteem can be a risk factor for young women's body image (Downs et al., 2006; Fingeret \& Gleaves, 2004). Thus, it is possible to predict that Instagram users' high levels of self-esteem may contribute to decreasing their body dissatisfaction.

As mentioned earlier, Instagram users' selfie-posting behavior may help to construct their positive self-image and beliefs about themselves, which may contribute to enhancing their self-esteem. It is also likely that enhanced selfesteem may lead to a decreasing in body dissatisfaction. Connecting previous studies reviewed above, Instagram users' self-esteem may play a mediating role in the relationship between their selfie-posting behavior and body dissatisfaction. Therefore, the following hypothesis is proposed:

H1: Self-esteem will mediate the relationship between selfie-posting behavior and body dissatisfaction such that (a) selfie-posting behavior will increase self-esteem, which will in turn (b) decrease body dissatisfaction. 


\section{Need for Popularity as a Moderator}

The need for popularity refers to people's desire to do something to appear popular (Santor et al., 2000). The need for popularity facilitates one's certain behaviors to be accepted by peer groups and build relationships with peers (Santor et al., 2000). As previously stated, SNS platforms provide individuals with capabilities for presenting themselves in a selective way to a large number of friends or followers (Manago et al., 2008; Zhao et al., 2008). In this regard, SNS is considered as an ideal venue for achieving a high popularity (Utz et al., 2012). According to Zywica and Danowski (2008), extroverted SNS users with higher self-esteem already enjoy high popularity offline and try to reinforce their popularity on SNS, whereas introverted users with low self-esteem strive to appear more popular on SNS to compensate their low popularity offline.

SNS users with a high need for popularity are more likely to disclose information about themselves (Christofides et al., 2009). Moreover, they tend to present more idealized images of themselves for increasing their popularity on their online networks (Utz \& Beukeboom, 2011). Utz et al. (2012) provided empirical evidence that SNS users with a higher need for popularity more frequently engage in profile enhancement and strategic self-presentation to affect others' perceptions about themselves.

The need for popularity is also positively related to the frequency of selfie-posting (J. W. Kim \& Chock, 2017). SNS users gauge their popularity on online networks based on quantitative measures of feedback from others (Chua \& Chang, 2016; Jin \& Muqaddam, 2018). Therefore, those with a high need for popularity may post more carefully selected and edited or retouched selfies to receive a great number of "likes," "followers," and "comments." (Chae, 2017; Chua \& Chang, 2016; Fox \& Vendemia, 2016; Haferkamp \& Krämer, 2011; Mascheroni et al., 2015). This suggests that when Instagram users with a high need for popularity post selfies, they may be more concerned about others' evaluation of themselves rather than the self-evaluation.

In contrast, those with a low need for popularity may post their selfies for self-affirming positive aspects of their physical appearance rather than receiving positive feedback from others. Therefore, when Instagram users with a low need for popularity take and upload selfies more frequently, they may be able to take more advantages of enhancing their self-esteem than those with a high need for popularity. This suggests that Instagram users' levels of the need for popularity could condition the influence of selfie-posting behavior on self-esteem. Thus, the following hypothesis is posited:

H2: The need for popularity will moderate the influence of selfie-posting behavior on self-esteem, such that the influence of selfie-posting behavior is greater for those with lower levels than higher levels of the need for popularity.

Figure 1. Conceptual Model of the Conditional Indirect Effect of Instagram Users' Selfie-Posting Behavior on Their Body Dissatisfaction Through Their Self-Esteem.

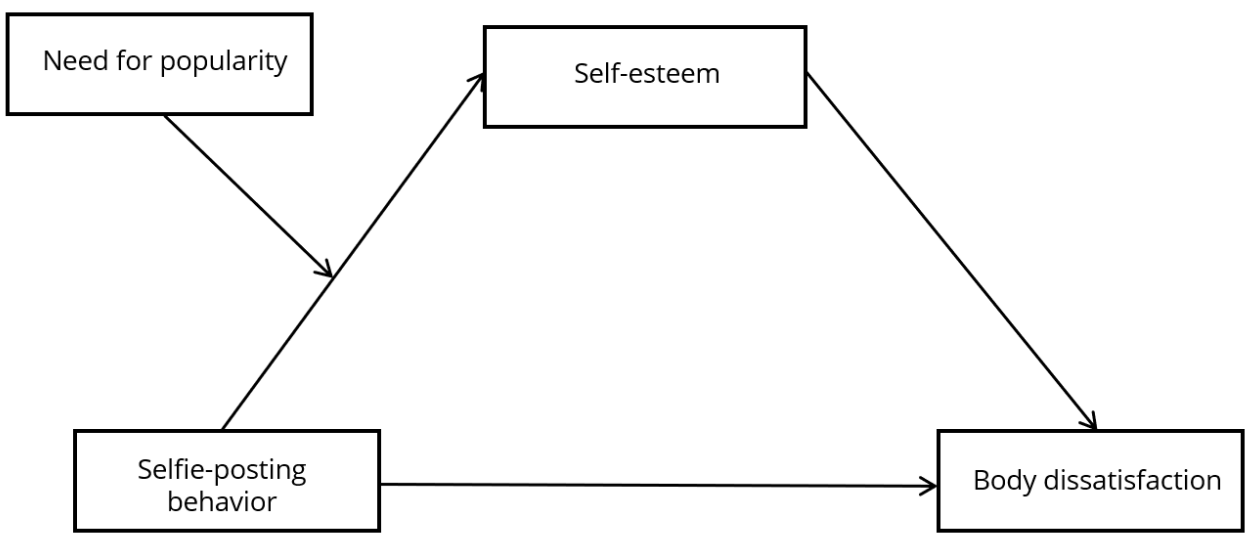

Finally, drawing on the discussions above, the researcher tests a moderated mediation model of Instagram users' selfie-posting and body dissatisfaction. Summarizing the arguments given above, it is likely that the need for 
popularity moderates the indirect relationship between selfie-posting and body dissatisfaction through selfesteem (See Figure 1). Therefore, the following hypothesis is proposed:

H3: The need for popularity will moderate the mediation of self-esteem, such that the indirect effect of selfieposting behavior via self-esteem is greater for those with lower levels than higher levels of the need for popularity.

\section{Method}

\section{Study Context}

This investigation was conducted in the context of a particular SNS platform, Instagram in South Korea in July 2017. This is because Instagram designed for posting and sharing images has become a more primary channel for posting selfies compared to other SNS platforms such as Facebook and Twitter (Fardouly et al., 2018). Young adults (ages 18 to 29) are the highest Instagram users and females use Instagram more frequently than males in South Korea (Korea Press Foundation, 2019). Besides, body image concerns including body dissatisfaction are prevailing among female college students (Neighbors \& Sobal, 2007). Therefore, this study was conducted with female college students from South Korea.

\section{Participants}

An online survey was conducted to test the proposed hypotheses. Participants were recruited from a survey panel of a research firm in South Korea. The company advertised this survey by sending an email invitation to its panel members. Only female college students who have an existing Instagram account were allowed to sign up for this survey. Participants who completed the survey received a reward of \$1.5.

A total of 321 female college students participated in this survey. Participants' mean age was $21.29(S D=1.61)$. The mean of body mass index (BMl: $\left.\mathrm{kg} / \mathrm{m}^{2}\right)$ was $20.58(S D=2.75$, range $=15.43-30.85)$, which falls in the normal weight range (World Health Organization, 2006).

\section{Measurements}

\section{Selfie-Posting Behavior}

Consistent with J. W. Kim and Chock (2017), participants' selfie-posting behavior was assessed by following two questions: "how often do you take photographs of yourself?" and "how often do you post photographs of yourself on your Instagram page?" (1: never, 7: very frequently). Responses were averaged to produce a selfie-posting index $(a=.82 M=3.56, S D=1.45)$.

\section{Self-Esteem}

The Rosenberg self-esteem scale (Rosenberg, 1965) was used to measure participants' self-esteem. Participants were directed to indicate how much they agreed with ten statements including "I feel that I'm a person of worth, at least on an equal plane with others" and "I feel that I have a number of good qualities." Following Wang et al. (2017), items were scored on a 7-point Likert scale ( 1 = strongly disagree, 7 = strongly agree). Relevant items were reversely coded. After reverse-coding, the average of all responses was calculated to use as a self-esteem index (a $=.87, M=4.45, S D=.94)$.

\section{Body Dissatisfaction}

Participants' body dissatisfaction was gauged using a subscale of the Eating Disorder Inventory (EDI; Garner et al., 1983). The body dissatisfaction subscale consists of nine items such as "I think my stomach is too big" and "I think that my thighs are too large" $(1=$ never, $6=$ always $)$. After reverse-coding some items, responses were averaged to create an index of body dissatisfaction ( $\alpha=.84, M=4.09, S D=.95)$. 


\section{Need for Popularity}

To measure the need for popularity, participants were directed to report the extent to which they agreed with twelve items from Santor et al.'s study (2000). Examples include: "I have done things to make me more popular, even when it meant doing something I would not usually do," "At times, I have ignored some people in order to be more popular with others," and "It is important that people think I am popular." (1: strongly disagree, 7: strongly agree). The twelve items offered a high reliability and all responses were averaged $(\alpha=.92, M=2.93, S D=1.15)$.

\section{Control Variables}

Prior research has shown that SNS use is closely related to young women's body image (e.g., Tiggemann \& Miller, 2010). Therefore, Instagram use was measured to control. Consistent with a previous study (Fardouly et al., 2018), participants' Instagram use was assessed with the following two questions: "How often do you check Instagram?" (1: not at all, 2: every few days, 3: once a day, 4: every few hours, 5: every hour, 6: every 30 minutes, 7: every 10 minutes, 8: every 5 minutes) $(M=3.66, S D=1.27)$ and "how long do you spend on Instagram on a typical day?" ( $1=5$ minutes or less, $2=15$ minutes, $3=30$ minutes, $4=1$ hour, $5=2$ hours, $6=3$ hours, $7=4$ hours, $8=5$ hours, $9=6$ hours, $10=$ 7 hours, $11=8$ hours, $12=9$ hours, $13=10$ hours or more $)(M=3.30, S D=1.81)$. Responses to the two questions were highly correlated $(r=.61, p<.001)$. These two questions were assessed by scales with different ranges. Thus, standard scores (i.e., z score) of these responses were calculated and averaged to create an index of Instagram use (range $=-1.68$ to 3.99 ).

Young women's age and BMI have been found to influence their body image (Cohen et al., 2018). Thus, both were measured to control. Participants were asked to report their age, height, and weight. BMI was calculated using height and weight information.

\section{Results}

As a preliminary analysis, bivariate correlations between all variables were calculated (See Table 1). Then, the proposed hypotheses were tested using PROCESS macro (Version 3) for SPSS (Hayes, 2013). Analyses for mediation $(\mathrm{H} 1)$, moderation $(\mathrm{H} 2)$, and moderated mediation $(\mathrm{H} 3)$ were conducted with the PROCESS models. The control variables aforementioned were entered into all analyses.

Table 1. Bivariate Correlations Among All Study Variables.

\begin{tabular}{lccccccc}
\hline & 1 & 2 & 3 & 4 & 5 & 6 & 7 \\
\hline 1. Age & 1 & & & & & & \\
2. Instagram use & $.172^{* *}$ & 1 & & & & & \\
3. BMI & -.002 & -.087 & 1 & & & & \\
4. Selfie-posting & -.065 & $.275^{* *}$ & $-.147^{* *}$ & 1 & & & \\
5. Self-esteem & -.001 & .057 & -.032 & $.156^{* *}$ & 1 & & \\
6. Body dissatisfaction & -.052 & -.071 & $.514^{* *}$ & $-.196^{* *}$ & $-.294^{* *}$ & 1 & \\
7. Need for popularity & -.032 & $.144^{*}$ & $-.130^{*}$ & $.244^{* *}$ & $-.145^{* *}$ & $-.110^{*}$ & 1 \\
\hline Note. ${ }^{*} p<.05,{ }^{* *} p<.01$ & & & & & & &
\end{tabular}

Hypothesis 1 predicted that Instagram users' self-esteem will mediate the relationship between their selfie-posting and body dissatisfaction. A mediation test was conducted using the PROCESS model 4, controlling for participants' age, BMI, and Instagram use. Results showed that more frequent taking and posting of selfies on Instagram were related to higher levels of self-esteem $(b=.11, S E=.04, t=2.48, p=.013)$. In addition, greater self-esteem was connected with low levels of body dissatisfaction $(b=-.27$, SE $=.05, t=-5.3, p<.001)$.

95\% bias-corrected confidence interval (Cl) based on 10,000 bootstrap samples was employed to investigate a mediating role of self-esteem. A significant mediating effect was found, such that Instagram users' selfie-posting behavior indirectly decreases their body dissatisfaction by increasing their self-esteem $(b=-.03$, Boot $S E=.01,95 \%$ $\mathrm{Cl}[-.052,-.006])$. A Sobel indirect effect test also showed that the mediating effect of self-esteem on the 
relationship between Instagram selfie-posting and body dissatisfaction was significant (Sobel $Z=-2.22, p=.027$ ). The direct effect of Instagram selfie-posting on body dissatisfaction was not significant $(b=-.06, S E=.03, t=-1.78$, $p=.08$ ). Therefore, hypothesis 1 was supported.

Hypothesis 2 predicted that Instagram users' need for popularity will moderate the influence of selfie-posting on self-esteem. A moderation test (the PROCESS model 1) was conducted treating the need for popularity as a moderating variable, controlling for participants' age, BMI, and Instagram use. Results indicated that an interaction effect between Instagram selfie-posting and the need for popularity on self-esteem was significant and negative $(b=-.07, S E=.03, t=2.97, p<.01)$. To examine this interaction, values of the moderator were categorized into three groups (i.e., a group at the mean, groups plus and minus one standard deviation from the mean). As shown in Figure 2, the positive effect of Instagram selfie-posting on self-esteem was significant only for those with low (Mean - 1SD) $(b=.21, S E=.05, t=3.83, p<.001)$ and moderate (Mean) $(b=.12, S E=.04, t=2.97, p<.01)$ levels of the need for popularity. The effect was not significant among those who have high levels of the need for popularity $($ Mean $+1 S D)(b=.03, S E=.05, t=.67, p=.50)$. These results showed that the positive effect of Instagram users' selfie-posting on their self-esteem was conditional on individual differences in the need for popularity. Therefore, hypothesis 2 was confirmed.

Figure 2. The Need for Popularity as a Moderator of the Relationship Between Instagram Users' Selfie-Posting Behavior and Their Self-Esteem.

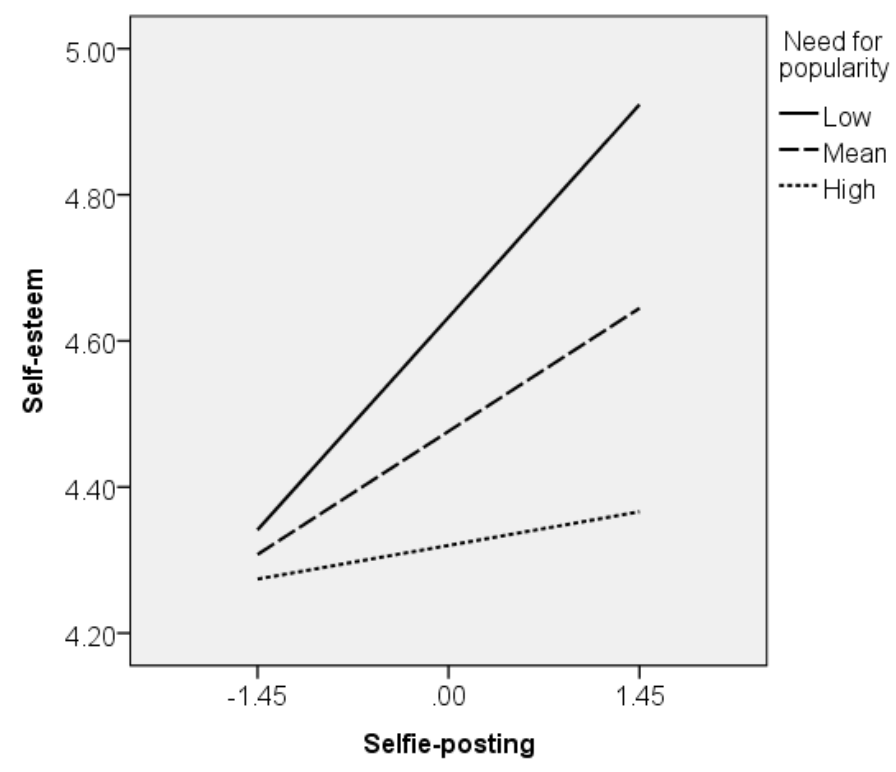

Note. Selfie-posting and the need for popularity were mean-centered prior to analysis.

Hypothesis 3 predicted that Instagram users' need for popularity will moderate the indirect influence of Instagram selfie-posting on body dissatisfaction via self-esteem. As shown in Figure 3, a moderated mediation effect was analyzed with the PROCESS model 7, controlling for participants' age, BMI, and Instagram use (See Table 2). The index of moderated mediation showed that the indirect effect of Instagram selfie-posting on body dissatisfaction via self-esteem is significantly moderated by self-esteem (index $=.02, S E=.02,95 \% \mathrm{Cl}[.007, .038]$ ). 
Figure 3. Moderated Mediation Effect: Indirect Relationship Between Instagram Users'Selfie-Posting Behavior and Their Body Dissatisfaction Through Self-Esteem That is Moderated by Their Need for Popularity.

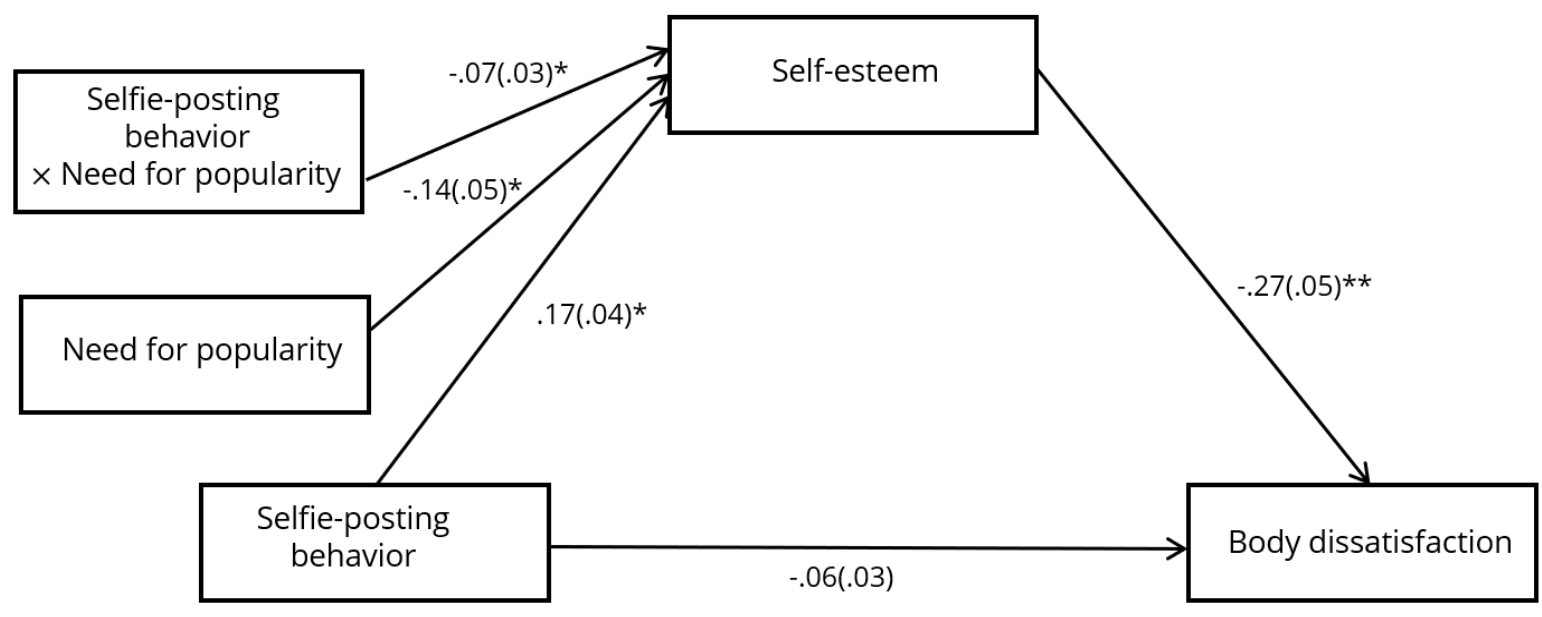

Note. Path coefficients are unstandardized (Standard errors in parentheses).

$$
*_{p}<.05 ; * * p<.001 \text {. }
$$

Table 2. Regression Results From the Moderated Mediation Model (PROCESS Model 7) for Predicting Self-Esteem and Body Dissatisfaction ( $N=321)$.

\begin{tabular}{|c|c|c|c|c|}
\hline & \multicolumn{2}{|c|}{ Self-esteem } & \multicolumn{2}{|c|}{ Body dissatisfaction } \\
\hline & $b(S E)$ & $p$ & $b(S E)$ & $p$ \\
\hline \multicolumn{5}{|l|}{ Control variables } \\
\hline Age & $.00(.04)$ & .951 & $-.04(.03)$ & .187 \\
\hline BMI & $-.01(.02)$ & .676 & $.17(.02)^{\star \star}$ & .000 \\
\hline Instagram use & $.03(.06)$ & .579 & $.02(.06)$ & .665 \\
\hline \multicolumn{5}{|l|}{ Conceptual variables } \\
\hline Selfie-posting & $.17(.04)^{\star}$ & .003 & $-.06(.03)$ & .077 \\
\hline Need for popularity & $-.14(.05)^{\star}$ & .004 & & \\
\hline Selfie-posting $\times$ Need for popularity & $-.07(.03)^{\star}$ & .007 & & \\
\hline Self-esteem & & & $-.27(.05)^{\star \star}$ & .000 \\
\hline Constant & $4.6(.82)$ & .000 & 2.54(.78) & .001 \\
\hline$R^{2}$ & .08 & .000 & .35 & .000 \\
\hline
\end{tabular}

Specifically, as demonstrated in Table 3, the negative indirect effect of Instagram selfie-posting on body dissatisfaction through self-esteem was significant when users' need for popularity is low (Mean - 1SD) $(b=-.05, S E$ $=.02,95 \% \mathrm{Cl}[-.090,-.026])$ and moderate (Mean) $(b=-.03, S E=.01,95 \% \mathrm{Cl}[-.058,-.011]$. The indirect effect was not significant among those with high levels of the need for popularity (Mean $+1 S D)(b=-.01, S E=.01,95 \% \mathrm{Cl}[-.036$, $.016]$ ). These results showed that the indirect effect of Instagram users' selfie-posting on their body dissatisfaction via self-esteem was manifest only when their need for popularity was low or moderate. Thus, hypothesis 3 was supported. 
Table 3. The Conditional Indirect Effect of Selfie-Posting on Body Dissatisfaction via Self-Esteem Depending on Values of the Need for Popularity.

\begin{tabular}{lcc}
\hline Need for popularity & Indirect effect(Boot SE) & Boot 95\% Cl \\
\hline Low & $-.05(.02)$ & {$[-.090,-.026]$} \\
Medium & $-.03(.01)$ & {$[-.058,-.011]$} \\
High & $-.01(.01)$ & {$[-.036, .016]$} \\
\hline
\end{tabular}

Note. For the need for popularity, low, medium, and high categorizations refer to one standard deviation below the mean, the mean, and one standard deviation above the mean respectively. $S E=$ standard error. $\mathrm{Cl}=$ confidence interval. Bootstrapped standard errors and confidence intervals were computed using 10,000 bootstrap samples.

\section{Discussion}

This study explored a mediating role of self-esteem in the relationship between Instagram users' selfie-posting behavior and their body dissatisfaction. Moreover, this study examined whether this mediating relationship is contingent upon Instagram users' need for popularity. As expected, the results of this study support the proposed indirect effect model, indicating that Instagram users' selfie-posting behavior decreases their body dissatisfaction by enhancing their self-esteem. Such an indirect effect was significant only for those with low or moderate levels of the need for popularity.

This study provides several implications for the literature on selfies and body image. First of all, this study extended prior research by directly investigating the effect of selfie-posting behavior on young women's self-esteem and body image concerns. Previous studies regarding SNS users' selfie-posting have mainly explored the predictors of selfie-posting such as narcissism (J. W. Kim \& Chock, 2017) and personal traits (Sorokowska et al., 2016). Little studies have examined young women's selfie-posting behavior as a determinant of self-esteem and body image concerns. Drawing on the positive illusion theory (S. E. Taylor \& Armor, 1996), this study provides evidence that young women's selfie-posting behavior can contribute to enhancing their self-esteem and decreasing their body dissatisfaction. Instagram users' selfie-posting behavior as an act of positive self-presentation seems to produce positive illusions of themselves. Such positive illusions appear to play a pivotal role in boosting self-esteem but reducing body image concerns.

These findings are particularly important given growing concerns about the negative effects of selfie activities on young women's body image (Mills et al., 2018; Tiggemann et al., 2020). Prior research has shown that exposure to Instagram selfies negatively influences young women's body image (Chang et al., 2019; Wang et al., 2019; J. Yang et al., 2020). Instagram users are not only viewing others' selfies but also post their own selfies. The findings of this study show that unlike passive viewing of others' selfies, selfie-posting activity may have a positive impact on young women's self-esteem and body image. This contributes to a deeper understanding of the nuanced relationships between different types of Instagram selfie activities (e.g., viewing and posting) and young women's body image concerns.

Second, to my knowledge, the current study is the first to examine explanatory mechanisms underlying the relationship between selfie-posting behavior and body image concerns. Extending previous studies that explored whether selfie-posting is associated with body image concerns (Butkowski et al., 2019; Chang et al., 2019; Cohen et al., 2018; Ridgway \& Clayton, 2016), this study shows that Instagram users' self-esteem mediates the relationship between their selfie-posting behavior and body dissatisfaction. The direct effect of selfie-posting on body dissatisfaction was not found. These findings indicate that the relationship between selfie-posting behavior and body dissatisfaction is not simple. A notable finding of this study is the critical role that self-esteem plays in reducing young women's body dissatisfaction. This finding suggests that individuals' self-esteem matters in the relationship between their selfie-posting behavior and body image concerns.

Third but more important, the current study provides insights into boundary conditions of selfie-posting effects. As of yet, no study has explored individual differences in selfie-posting effects on body image concerns. A contribution of this study lies in its investigation of the need for popularity as a potential moderator of the relationships among selfie-posting behavior, self-esteem, and body dissatisfaction. This study indicated that the positive effect of selfie-posting on self-esteem was significant only among those with low or moderate levels of 
the need for popularity. Furthermore, the indirect effect of selfie-posting on body dissatisfaction via self-esteem was also found only among those with a low or moderate need for popularity.

For those with high levels of the need for popularity, selfie-posting behavior was not related to self-esteem and body dissatisfaction. Instagram users with a high need for popularity might be more concerned with their appearance and conscious of how others see themselves. They might consider the feedback to their selfies as a reliable barometer of their physical attractiveness and high popularity (Chua \& Chang, 2016). For attracting more positive feedback to selfies, they may not only edit their selfies more but also over-scrutinize or ruminate on their selfies and the feedback they receive. The great number of likes and positive comments individuals receive on their selfies may lead to positive self-evaluations (Burrow \& Rainone, 2017). However, prior research suggests that users who highly value or invest others' feedback to their selfies may not experience such positive effects of the feedback (Butkowski et al., 2019). As mentioned above, Instagram users with a high need for popularity may be more likely to care about other people's feedback to their selfies, which might make themselves less susceptible to the positive effects of that feedback than those who are less concerned with their popularity.

In contrast, those with a low need for popularity may not care too much about others' evaluations or feedback. They may post selfies to satisfy their basic desire for protecting their self-worth by confirming positive facets of their appearance rather than gaining high popularity from others. Thus, for those with a low need for popularity, selfie-posting may be a useful way to enhance self-esteem and consequently alleviating body image concerns.

The present study has several limitations worth noting. First of all, the current study employed a cross-sectional survey to collect data. Thus, this study cannot guarantee the direction of causal relationships between variables. Experimental or longitudinal studies are needed to clarify the direction of the relationships between selfie-posting, self-esteem, and body image concerns. Second, this study used self-report measures that may produce social desirability and retrospective bias. Future research could employ qualitative research methods to ecologically validate the relationship between selfie-posting and body image concerns. Third, this study assessed selfie-posting behavior by asking the frequency of selfie-taking and posting. Even though selfie-taking and posting were highly related, both may have different effects on body image. Therefore, the findings of this study should be interpreted with caution. Also, this study tested the moderating role of the need for popularity. Instagram users' need for popularity may be closely related to the number of followers. Future studies need to consider the number of followers as a control variable. Furthermore, I assumed Instagram users who post selfies would beautify their selfies before posting them on Instagram. Such an assumption was not tested directly in this study. This assumption might be addressed in future studies. Finally, this study was limited to one SNS platform, Instagram, and one user group, female college students. Thus, the results of the present study may not be generalizable to different SNS platforms or different groups of Instagram users.

In conclusion, the findings of this study indicate that young women's selfie-posting behavior can reduce their body image concerns by enhancing their self-esteem. Such indirect effects of selfie-posting behavior could be manifest only among those who do not care too much about their popularity from others. The findings point to the subtle ways in which young women's selfie-posting behavior can influence their body image.

\section{References}

Bem, D. (1972). Self-perception theory. In L. Berkowitz (Ed.), Advances in experimental social psychology (Vol. 6, pp. 2-57). Academic Press.

Bergman, S. M., Fearrington, M. E., Davenport, S. W., \& Bergman, J. Z. (2011). Millennials, narcissism, and social networking: What narcissists do on social networking sites and why. Personality and Individual Differences, 50(5), 706-711. https://doi.org/10.1016/j.paid.2010.12.022

Burrow, A. L., \& Rainone, N. (2017). How many likes did I get? Purpose moderates links between positive social media feedback and self-esteem. Journal of Experimental Social Psychology, 69, 232-236.

https://doi.org/10.1016/j.jesp.2016.09.005 
Butkowski, C. P., Dixon, T. L. \& Weeks, K. (2019). Body surveillance on Instagram: Examining the role of selfie feedback investment in young adult women's body image concerns. Sex Roles, 81(5-6), 385-397.

https://doi.org/10.1007/s11199-018-0993-6

Chae, J. (2017). Virtual makeover: Selfie-taking and social media use increase selfie editing frequency through social comparison. Computers in Human Behavior, 66, 370-376. http://dx.doi.org/10.1016/j.chb.2016.10.007

Chang, L., Li, P., Loh, R. S. M., \& Chua, T. H. H., (2019). A study of Singapore adolescent girls' selfie practices, peer appearance comparisons, and body esteem on Instagram. Body Image, 29, 90-99.

https://doi.org/10.1016/j.bodyim.2019.03.005

Christofides, E., Muise, A., \& Desmarais, S. (2009). Information disclosure and control on Facebook: Are they two sides of the same coin or two different processes? CyberPsychology \& Behavior, 12(3), 341-345.

https://doi.org/10.1089/cpb.2008.0226

Chua, T. H. H., \& Chang, L. (2016). Follow me and like my beautiful selfies: Singapore teenage girls' engagement in self-presentation and peer comparison on social media. Computers in Human Behavior, 55(Part A), 190-197. http://dx.doi.org/10.1016/j.chb.2015.09.011

Cohen, R., Newton-John, T., \& Slater, A. (2018). 'Selfie'-objectification: The role of selfies in self-objectification and disordered eating in young women. Computers in Human Behavior, 79, 68-74.

https://doi.org/10.1016/j.chb.2017.10.027

Dhir, A., Pallesen, S., Torsheim, T., \& Andreassen, C. S., (2016). Do age and gender differences exist in selfierelated behaviours? Computers in Human Behavior, 63, 549-555. https://doi.org/10.1016/j.chb.2016.05.053

Downs, D. M., James, S., \& Cowan, G. (2006). Body objectification, self-esteem, and relationship satisfaction: A comparison of exotic dancers and college women. Sex Roles, 54(11-12), 745-752. https://doi.org/10.1007/s11199006-9042-y

Fardouly, J., \& Rapee, R. M. (2019). The impact of no-makeup selfies on young women's body image. Body Image, 28, 128-134. https://doi.org/10.1016/j.bodyim.2019.01.006

Fardouly, J., Willburger. B. K., \& Vartanian. L. R. (2018). Instagram use and young women's body image concerns and self-objectification: Testing mediational pathways. New Media \& Society, 20(4), 1380-1395.

https://doi.org/10.1177/1461444817694499

Fingeret, M. C., \& Gleaves, D. H. (2004). Sociocultural, feminist, and psychological influences on women's body satisfaction: A structural modeling analysis. Psychology of Women Quarterly, 28(4), 370-380.

https://doi.org/10.1111/j.1471-6402.2004.00154.x

Fitch, G. (1970). Effects of self-esteem, perceived performance, and choice on causal attributions. Journal of Personality and Social Psychology, 16(2), 311-315. https://doi.org/10.1037/h0029847

Fox, J., \& Vendemia, M. A. (2016). Selective self-presentation and social comparison through photographs on social networking sites. Cyberpsychology, Behavior, and Social Networking, 19(10), 593-600.

https://doi.org/10.1089/cyber.2016.0248

Frison, E., \& Eggermont, S. (2017). Browsing, posting, and liking on Instagram: The reciprocal relationships between different types of Instagram use and adolescents' depressed mood. Cyberpsychology, Behavior, and Social Networking, 20(10), 603-609. https://doi.org/10.1089/cyber.2017.0156

Garner, D. M., Olmstead, M. P., \& Polivy, J. (1983). Development and validation of a multidimensional eating disorder inventory for anorexia nervosa and bulimia. International Journal of Eating Disorders, 2(2), 15-34. http://doi.org/10.1002/1098-108X(198321)2:2<15::AID-EAT2260020203>3.0.CO;2-6 
Gibbs, J. L., Ellison, N. B., Heino, R. D. (2006). Self-presentation in online personals: The role of anticipated future interaction, self-disclosure, and perceived success in Internet dating. Communication Research, 33(2),152-177. https://doi.org/10.1177/0093650205285368

Haferkamp, N., \& Krämer, N. C. (2011). Social comparison 2.0: Examining the effects of online profiles on socialnetworking sites. Cyberpsychology, Behavior, and Social Networking, 14(5), 309-314.

https://doi.org/10.1089/cyber.2010.0120

Halpern, D., Katz, J. E. \& Carril, C. (2017). The online ideal persona vs. the jealousy effect: Two explanations of why selfies are associated with lower-quality romantic relationships. Telematics and Informatics, 34(1), 114-123. http://doi.org/10.1016/j.tele.2016.04.014

Hancock, J. T., \& Toma, C. L. (2009). Putting your best face forward: The accuracy of online dating photographs. Journal of Communication, 59(2), 367-386. https://doi.org/10.1111/j.1460-2466.2009.01420.x

Hayes, A. F. (2013). Introduction to mediation, moderation, and conditional process analysis: A regression-based approach. Guilford Press.

Hesse, B. W., Werner, C. M., \& Altman, I. (1988). Temporal aspects of computer-mediated communication. Computers in Human Behavior, 4(2), 147-165. https://doi.org/10.1016/0747-5632(88)90023-4

Jin, S. V., \& Muqaddam, A. (2018). "Narcissism 2.0! Would narcissists follow fellow narcissists on Instagram?" the mediating effects of narcissists personality similarity and envy, and the moderating effects of popularity. Computers in Human Behavior, 81, 31-41. https://doi.org/10.1016/j.chb.2017.11.042

Kelly, A. E., \& Rodriguez, R. R. (2006). Publicly committing oneself to an identity. Basic and Applied Social Psychology, 28(2), 185-191. https://doi.org/10.1207/s15324834basp2802_8

Kim, J., \& Lee, J.-E. R., (2011). The Facebook paths to happiness: Effects of the number of Facebook friends and self-presentation on subjective well-being. Cyberpsychology, Behavior, \& Social Networking, 14(6), 359-364. https://doi.org/10.1089/cyber.2010.0374

Kim, J. W., \& Chock, T. M. (2017). Personality traits and psychological motivations predicting selfie posting behaviors on social networking sites. Telematics and Informatics, 34(5), 560-571.

https://doi.org/10.1016/j.tele.2016.11.006

Kim, Y., \& Baek, Y. M. (2014). When is selective self-presentation effective? An investigation of the moderation effects of "self-esteem" and "social trust." Cyberpsychology, Behavior, and Social Networking, 17(11), 697-701. https://doi.org/10.1089/cyber.2014.0321

Korea Press Foundation. (2019). 언론 수용자 조사 [Media users in Korea 2019].

https://www.kpf.or.kr/synap/skin/doc.html?fn=BASE_202001301015249953.pdf\&rs=/synap/result/upload/media pds/

Manago, A. M., Graham, M. B., Greenfield, P. M., Salimkhan, G. (2008). Self-presentation and gender on MySpace. Journal of Applied Developmental Psychology, 29(6), 446-458. https://doi.org/10.1016/j.appdev.2008.07.001

Mascheroni, G., Vincent, J., \& Jimenez, E. (2015). “Girls are addicted to likes so they post semi-naked selfies": Peer mediation, normativity and the construction of identity online. Cyberpsychology: Journal of Psychosocial Research on Cyberspace, 9(1), Article 5. https://doi.org/10.5817/CP2015-1-5

Mendelson, A. L., \& Papacharissi, Z. (2010). Look at us: Collective narcissism in college student Facebook photo galleries. In Papacharissi, Z. (Ed.), The Networked Self: Identity, Community and Culture on Social Network Sites (pp. 251-273). Routledge. 
Mercurio, A. E., \& Landry, L. J. (2008). Self-objectification and wellbeing: The impact of self-objectification on women's overall sense of self-worth and life satisfaction. Sex Roles, 58(7-8), 458-466.

https://doi.org/10.1007/s11199-007-9357-3

Mills, J. S., Musto, S., Williams, L., \& Tiggemann, M. (2018). "Selfie" harm: Effects on mood and body image in young women. Body Image, 27, 86-92. http://dx.doi.org/10.1016/j.bodyim.2018.08.007

Neighbors, L. A., \& Sobal, J. (2007). Prevalence and magnitude of body weight and shape dissatisfaction among university students. Eating Behaviors, 8(4), 429-439. http://dx.doi.org/10.1016/j.eatbeh.2007.03.003

Paxton, S. J., Eisenberg, M. E., \& Neumark-Sztainer, D. (2006). Prospective predictors of body dissatisfaction in adolescent girls and boys: A five-year longitudinal study. Developmental Psychology, 42(5), 888-899.

https://doi.org/10.1037/0012-1649.42.5.888

Ridgway, J. L., \& Clayton, R. B. (2016). Instagram unfiltered: Exploring associations of body image satisfaction, Instagram \#selfie posting, and negative romantic relationship outcomes. Cyberpsychology, Behavior, and Social Networking, 19(1), 2-7. https://doi.org/10.1089/cyber.2015.0433

Rosenberg, M. (1965). Society and the adolescent self-image. Princeton University Press.

Santor, D. A., Messervey, D., \& Kusumakar, V. (2000). Measuring peer pressure, popularity, and conformity in adolescent boys and girls: Predicting school performance, sexual attitudes, and substance abuse. Journal of Youth and Adolescence, 29(2), 163-182. https://doi.org/10.1023/A:1005152515264

Schlenker, B. R., Dlugolecki, D. W., \& Doherty, K. (1994). The impact of self-presentations on self-appraisals and behavior: The power of public commitment. Personality and Social Psychology Bulletin, 20(1), 20-33. https://doi.org/10.1177/0146167294201002

Siibak, A. (2009). Constructing the self through the photo selection - Visual impression management on social networking websites. Cyberpsychology: Journal of Psychosocial Research on Cyberspace, 3(1), Article 1.

https://cyberpsychology.eu/article/view/4218/3260

Sorokowska, A., Oleszkiewicz, A., Frackowiak, T., Pisanski, K., Chmiel, A., \& Sorokowski, P. (2016). Selfies and personality: Who posts self-portrait photographs? Personality and Individual Differences, 90, 119-123. http://dx.doi.org/10.1016/j.paid.2015.10.037

Taylor, P. (2014, March 4). More than half of Millennials have shared a 'selfie'. Pew Research Center: Fact Tank. https://www.pewresearch.org/fact-tank/2014/03/04/more-than-half-of-millennials-have-shared-a-selfie/

Taylor, S. E., \& Armor, D. A. (1996). Positive illusions and coping with adversity. Journal of Personality, 64(4), 873898. https://doi.org/10.1111/j.1467-6494.1996.tb00947.x

Taylor, S. E., \& Brown, J. D. (1988). Illusion and well-being: A social psychological perspective on mental health. Psychological Bulletin, 103(2), 193-210. https://doi.org/10.1037/0033-2909.103.2.193

Tiggemann, M., Anderberg, I., \& Brown, Z. (2020). Uploading your best self: Selfie editing and body dissatisfaction. Body Image, 33, 175-182. https://doi.org/10.1016/j.bodyim.2020.03.002

Tiggemann, M., \& Miller, J. (2010). The Internet and adolescent girls' weight satisfaction and drive for thinness. Sex Roles, 63(1-2), 79-90. https://doi.org/10.1007/s11199-010-9789-z

Toma, C. L. (2013). Feeling better but doing worse: Effects of Facebook self-presentation on implicit self-esteem and cognitive task performance. Media Psychology, 16(2), 199-220.

https://doi.org/10.1080/15213269.2012.762189 
Toma, C. L., \& Hancock, J. T. (2010). Looks and lies: The role of physical attractiveness in online dating selfpresentation and deception. Communication Research, 37(3), 335-351. http://doi.org/10.1177/0093650209356437

Toma, C. L., \& Hancock, J. T. (2013). Self-affirmation underlies Facebook use. Personality and Social Psychology Bulletin, 39(3), 321-331. https://doi.org/10.1177/0146167212474694

Tylka, T. L., \& Sabik, N. J. (2010). Integrating social comparison theory and self-esteem within objectification theory to predict women's disordered eating. Sex Roles, 63(1-2), 18-31. https://doi.org/10.1007/s11199-010-97853

Utz, S., \& Beukeboom, C. J. (2011). The role of social network sites in romantic relationships: Effects on jealousy and relationship happiness. Journal of Computer-Mediated Communication, 16(4), 511-527.

https://doi.org/10.1111/j.1083-6101.2011.01552.x

Utz, S., Tanis, M., \& Vermeulen, I. (2012). It is all about being popular: The effects of need for popularity on social network site use. Cyberpsychology, Behavior, and Social Networking, 15(1), 37-42.

https://doi.org/10.1089/cyber.2010.0651

van den Berg, P., Paxton, S. J., Keery, H., Wall, M., Guo, J., \& Neumark-Sztainer, D. (2007). Body dissatisfaction and body comparison with media images in males and females. Body Image, 4(3), 257-268.

https://doi.org/10.1016/j.bodyim.2007.04.003

Vendemia, M. A., \& DeAndrea, D. C. (2018). The effects of viewing thin, sexualized selfies on Instagram: Investigating the role of image sources and awareness of photo editing practices. Body Image, 27, 118-127. http://doi.org/10.1016/j.bodyim.2018.08.013

Walther, J. B. (1996). Computer-mediated communication: Impersonal, interpersonal, and hyperpersonal interaction. Communication Research, 23(1), 3-44. https://doi.org/10.1177/009365096023001001

Wang, R., Yang, F., \& Haigh, M. M. (2017). Let me take a selfie: Exploring the psychological effects of posting and viewing selfies and groupies on social media. Telematics and Informatics, 34(4), 274-283.

http://doi.org/10.1016/j.tele.2016.07.004

Wang, Y., Fardouly, J., Vartanian, L. R., \& Lei, L. (2019). Selfie-viewing and facial dissatisfaction among Chinese adolescents: A moderated mediation model of general attractiveness internalization and body appreciation. Body Image, 30, 35-43. https://doi.org/10.1016/j.bodyim.2019.05.001

World Health Organization. (2006). Global database on Body Mass Index.

http://www.assessmentpsychology.com/icbmi.htm

Yang, C. (2016). Instagram use, loneliness, and social comparison orientation: Interact and browse on social media, but don't compare. Cyberpsychology, Behavior, and Social Networking, 19(12), 703-708.

https://doi.org/10.1089/cyber.2016.0201

Yang, J., Fardouly, J., Wang, Y., \& Shi, W. (2020). Selfie-viewing and facial dissatisfaction among emerging adults: A moderated mediation model of appearance comparisons and self-objectification. International Journal of Environmental Research and Public Health, 17(2), Article 672, https://doi.org/10.3390/ijerph17020672

Zhao, S., Grasmuck, S., Martin, J. (2008). Identity construction on Facebook: Digital empowerment in anchored relationships. Computers in Human Behavior, 24(5),1816-1836. https://doi.org/10.1016/j.chb.2008.02.012

Zywica, J., \& Danowski, J. (2008). The faces of Facebookers: Investigating social enhancement and social compensation hypotheses; predicting Facebook and offline popularity from sociability and self-esteem, and mapping the meanings of popularity with semantic networks. Journal of Computer-Mediated Communication, 14(1), 1-34. https://doi.org/10.1111/j.1083-6101.2008.01429.x 


\section{Correspondence to:}

Mihee Kim

Department of Media and Communication

Sejong University

209, Neungdong-ro, Gwangjin-gu

Seoul, 05006

South Korea

Email: mhkim2008(at)gmail.com

Editorial record: First submission received on December 24, 2018. Revisions received on August 2, 2019, June 2, 2020 and July 28, 2020. Accepted for publication on August 10, 2020.

Editor in charge: Lenka Dedkova

\section{About Authors}

Mihee Kim is an assistant professor in the Department of Media and Communication, Sejong University, South Korea. Her research interests include new media, body image, and media effects. 